\title{
The Role of Sports Activities in Improving the Level of Self- Esteem among Physically Disabled Athletes in Jordan
}

\author{
Dr. Khaled Yousef Asi \\ Assist. Professor of Special Education, College of Social Sciences, Al-Imam Muhammad Ibn Saud Islamic \\ University,
}

\begin{abstract}
The present study aimed to identify the role of sports activities in improving the level of self-esteem of physically disabled athletes in Jordan, as well as the differences according to the variables of gender and duration of injury. The study sample consisted of (64) members of the physically disabled athletes in Jordan, who were intentionally chosen. Self-Esteem Scale used and developed from Rosenberg Self-Esteem Scale (1979). The results showed that the mean of the role of sports activities in improving the level of self-esteem of physically disabled athletes in Jordan was (3.26) with medium level of esteem, the results also showed no statistically significant differences in the means of the estimates on the total instrument due to the variables of gender and duration of injury. The study recommended conducting similar studies on the physically disabled athletes of various sports, and taking into account the media aspects for the physically disabled athletes to maintain their self-esteem and raise their self-confidence.
\end{abstract}

Keywords: sports activities, the level of self-esteem, physically disabled athletes.

\section{Introduction}

Although the special education field programs recently emerged compared to other educational fields, it is witnessing a continuous and rapid developments, where papers, studies and the efforts of the specialists in that field are trying hard to discover everything that helps empower individuals with disabilities for inclusion in life experiences and community activities, and to consider them on the grounds that they are members of the community and not on the basis of their disability. The sports activities are one of the means that help empower individuals with disabilities to take their community role in their own learning and training, as well as in strengthening the nervous and muscular systems and to limitbone distraction, and assisting in the psychological, physical and social rehabilitation.

Rehabilitation and training programs, particularly sports activities, emerged to help them develop positive feelings about themselves and their self-estimation, the high self-esteem is the result of the positive trends of individuals about themselves (AlKholi, 2001). Ibrahim and Farhat (1998) defined sports activities as the different sports and games exercised by the individual with disabilities according to his ability due to the type and severity of disability.

Accordingly, practice of sports activities is one of the important methods in the formation of positive attitudes toward self and toward others, where it encourages appropriate social interaction and upgrading behavioral patterns for the better (Khoja, 2011). It is not just only sports activities, but it is a matter of learning appropriate social roles within the social norms and developing their sound moderate trends and behavior (Abdel-Hafeez and Bahi, 2001). Sport has social and psychological benefits in addition to its important role in strengthening the human body and preserving of motor mechanism, requiring the caretakers of individuals with motor disabilities to encourage them to practice different types of sports (Aldahri, 2005).

Studies have indicated that people with physical disabilities are trying to get rid of the inferiority feeling resulting from the failure of some organs, so they practice some sports activities to raise the self-esteem they have (Wetterhahn, Hanson and Levy, 2002)

In terms of physical disabilities, physical disability defined as a functional failure or an organic disorder obviously affecting the performance of the individual in his environment and requires therapeutic intervention or environmental modification. Thereby, individuals with physical disabilities are categorized within people with special needs (Solomon, 2001), including aspects of motor disorders such as spinal disorders, cases of cerebral palsy, epilepsy cases and cases of muscular dystrophy and other kinds (Roussan, 2007). Physical disability is a type of disability that is not limited to functional failure of organ, but extends to various aspects of the environment such as internal and external psychological social aspect of the physicallydisabled (Hassan, 2007) because their behavioral characteristics are directly influenced by reactions of others toward the aspects of their motor disorders, which generates a negative impact on their self-confidence and cause them stress (Alkakly, 2002) and (Roussan, 2007), resulting in negative impacton themselves and their self-confidence as confirmed by (Hassan, 2007) and (Bataineh and Muqableh, 2004). 
Studies show that disability was negatively linked to self-esteem of the disabled to reflect a sense of inferiority and lack of social competence, which generates a lowerself-esteemthan that of individuals without disabilities (Teri, 2000), this can be explained in light of the emotional imbalance and lack of psychological adjustment resulted from organ deficit or failure leading to anxiety and worry (Farhat, 2014)

Abu-Assad (2009) confirmed that high self-esteem is a positive attitude and low self-esteem represents a negative attitude. Emotions and feelings are the motivation that earns us a strong and distinct personality or weak personality, because the individual's giving positively or negatively affected by self-esteemshown in his behavior (Aldhidan, 2003). The self-esteem connects personal integration with the individual's ability to respond under such different situations; so individuals with high self-esteemhave integrated personality helping them perform their roles efficiently within community (Momni, 2006).

Consequently, the author of the current study believes that whenever the individual has a high selfesteem, then he/she will havea high positive feeling toward himself and community and vice versa, thus preventing psychological adjustment, social integration resulting in emotional and behavioral disorders.

In this regard, several studies have addressed the importance of exercise on the self-esteem of the physically disabled, including Beher and Menotti (2000) who confirmed that the practice of basketball at wheelchairs for physically disabled athletes have contributed to improving the level of self-esteem they have and coping with their disability. Oates (2004) assured the effectiveness of a swimming program on improving self-esteem among the physically disabled. Abu Obeid (2004) emphasized on the role of an educational program in the swimming and its impact on raising the skill level and increasing the level of self-concept among people with motordisabilities and challenges in Jordan. Cazenave, Peultier and Lefort (2008) confirmed the impact of sports activities on improving self-esteem among the physically disabled, where it contributed to raise the selfesteem from the low-level to mid-level, and did not show any differences due to gender and the presence of differences in the duration of the injury in favor ofthe severe.

Alwan (2006) indicated the importance of sports activities to improve the level of self-esteem among the physically disabled, where the results of the study have shown the existence of statistically significant differences in the degree of self-esteem among the physically disabled in favor of practitioners of sports activity. Khoja (2011) revealed that the practice of the sports activities contributes to improving body shape and selfesteem among the physically disabled, and it did not show differences in the variable of gender.

Therefore, the author desired to conduct this study, which aimed to investigate the role of sports activities to improve the self-esteem of physically disabled athletes in Jordan, according to the variables of gender and duration of the injury, and to demonstrate the positive impact of sports activities among people with motor disabilities in self-esteem.

\section{Statement of the problem}

Conducting the current study is needed to determine the role of sports activities in improving the self-esteem of physically disabled athletes in Jordan. This study attempted to answer the following questions:

1. What is the role of sports activities in improving the level of self-esteem among physically disabled athletes in Jordan?

2. Are there any significant differences $(a=0.05)$ in the role of sports activities in improving the level of selfesteem among physically disabled athletes in Jordan due to the variable of gender?

3. Are there any significant differences $(a=0.05)$ in the role of sports activities in improving the level of selfesteem among physically disabled athletes in Jordan due to the variable of duration of injury ( $\leq 5$ years)and $(>5$ years $)$ ?

\section{Significance}

The significance of the study lies in benefiting the relevant institutions to care for the physically disabled through the adoption of methods and strategies to improve self-esteem, as well as drawing the attention of the communities and families of people with motor disabilities to adopt sporting activities that contribute to improving self-esteem. The study also urges communities to include people with motor disabilities to improve their self-esteem and stay away from negative behaviors towards themselves and towards others.

\section{Methodology and procedures}

This section deals with a detailed description of the study methodology, population, the sample and instrument, shown as follows:

\section{Method}

Descriptive and survey approach adopted in the current survey, which qualitatively and quantitatively depicts the reality through answering the questions of the study using self-esteem scale. 
The Role of Sports Activities in Improving the Level of Self-Esteem among Physically Disabled..

\section{Sampling}

The study was applied to a sample of (64) members of the physically disabled athletes in Jordan,intentionally chosen for the academic year 2015/2016. The participants distributed according to the variables of the study:gender and duration of the injury, as shown in Table (1).

Table (1): Distribution of study sample according to the variables

\begin{tabular}{|l|l|l|l|}
\hline Variables & Groups & Frequency & Percentage \\
\hline \multirow{2}{*}{ Gender } & Male & 40 & $62.5 \%$ \\
\cline { 2 - 4 } & Female & 24 & $37.5 \%$ \\
\hline & ( $\leq 5$ years $)$ & 35 & $54.9 \%$ \\
\hline Duration of injury & (> 5 years) & 29 & $45.1 \%$ \\
\hline Total & 64 & $100.0 \%$ \\
\hline
\end{tabular}

\section{Instrument}

To identify the role of sports activities in improving the level of self-esteem of physically disabled athletes in Jordan, Self-Esteem Scale used and developed from Rosenberg Self-Esteem Scale (1979) (Kafafy, 1997).Having verified its validity and reliability, the Self-Esteem Scale, in its final draft, consisted of (10) paragraphs. The responder checks each paragraph on a scale of five degrees, namely, (strongly agree, agree, neutral, disagree, and strongly disagree), the scale corrected by giving the following weights, respectively $(5,4$, 3,2 and 1) for the above mentioned degrees. The following statistical criterion utilized for evaluating and judging the responder level on a scale of self-esteem through using the following equation:

Group length $=\underline{\text { maximum limit }- \text { minimum limit }(\text { for regression })}=5-1 / 3=4 / 3=1.33$

Low level: $(1-2.33)$

$$
\text { Number of groups }
$$

Medium level: (2.34 to less than 3.67)

High level: (more than 3.67)

\section{Validity}

To verify the validity of the self-esteem scale, the first draft was reviewed and evaluated by ten reviewers, more experienced in special education, psychology and measurement and evaluation in Jordanian Universities, where they were asked to check the appropriateness of the paragraphs (items) and to make sure of the language and the appropriateness of the instrument to achieve the study objectives. In light of the views and suggestions of the evaluators, the required modifications were made with agreement percentage $(80 \%)$, and the final draft consisted of (10) paragraphs.

\section{Reliability}

The reliability of the instrument was verified by the method of (test-retest), where it was applied to a pilot sample numbered (20) physically disabled athletes in Jordan, with two weeks interval between first and second application/test. Pearson correlation coefficient was calculated between the scores of respondents and the total reliability coefficient of the instrument was $(0.80)$. The second method conducted by calculating of the internal consistency coefficient (Cronbach's Alpha) of the total scale $=(0.88)$. These are considered appropriate values for achieving the objectives of the study.

\section{Results}

Results of the first question: What is the role of sports activities in improving the level of self-esteem among physically disabled athletes in Jordan?To answer this question, the arithmetic means and standard deviations calculated for the paragraphs of self-esteem scale and on the total scale, as shown in Table (2):

Table (2): the arithmetic means and standard deviations of the estimates in descending order

\begin{tabular}{|c|c|c|c|c|}
\hline No. of paragraph & Paragraph & Mean & St. D & Degree \\
\hline 2 & After practicing of sporting activities, I feel having a number of good qualities. & 3.71 & 0.52 & High \\
\hline 3 & Sports activities helped me feel successful & 3.69 & 0.47 & High \\
\hline 4 & Sports activities helped me be able to do things done by others. & 3.63 & 0.65 & Medium \\
\hline 7 & After I had practiced sports activities, I was satisfied. & 3.40 & 0.55 & Medium \\
\hline 5 & Sports activities helped me feel proud of having a lot to do & 3.29 & 0.67 & Medium \\
\hline 8 & Sports activities helped me get so much respect for myself & 3.26 & 0.78 & Medium \\
\hline 10 & Whenever I practiced sports activities, I felt well & 3.06 & 1.14 & Medium \\
\hline 9 & Sports activities made me feel important. & 3.05 & 0.94 & Medium \\
\hline 1 & Sports activities helped me feel valued, or at least equal to others & 2.89 & 0.87 & Medium \\
\hline 6 & Sports activities helped me develop a positive vision for myself & 2.71 & 0.71 & Medium \\
\hline \multicolumn{2}{|r|}{ Sp } & 3.26 & 0.40 & Medium \\
\hline
\end{tabular}


Table (2) showed that the means ranged between (2.71)and(3.71) and the degree of esteem ranged between (medium) and (high), where paragraph (2) which states "After practicing of sporting activities, I feel having a number of good qualities." in ranked the first place with an arithmetic mean (3.71) and a standard deviation (0.52) and high level of esteem, while paragraph (3) which states "Sports activities helped me feel successful" in the second place with a mean (3.69) and a standard deviation (0.47) and high level of esteem, paragraph (6) "Sports activities helped me develop a positive vision for myself " got the last place with a mean (2.71) and standard deviation (0.71) and medium level of esteem. The total scores of the participantsfor the role of sports activities in the level of self-esteem of physically disabled athletes in Jordan reached a mean (3.26) and a standard deviation (0.40) with medium level of esteem.

The results of the second question: Are there any significant differences $(a=0.05)$ in the role of sports activities in improving the level of self-esteem among physically disabled athletes in Jordan due to the variable of gender? To answer this question,means and standard deviations, and T-test utilized to calculate the estimates of the study sample on the total scalefor the role of sports activities in improving the level of self-esteem of physically disabled athletes in Jordan, according to gender, as shown intable (3).

Table (3): means, standard deviations, and (t-test) according to the gender variable

\begin{tabular}{|l|l|l|l|l|l|l|l|}
\hline Total scale & Gender & No. & Mean & St. D & T-value & Freedom degree & Sig. level \\
\hline \multirow{2}{*}{ Total level of self-esteem } & Male & 40 & 3.31 & 0.34 & 1.689 & 62 & 0.101 \\
\cline { 2 - 5 } & Female & 24 & 3.02 & 0.57 & & & \\
\hline
\end{tabular}

*Statistically significant at the significance level $(\square=0.05)$

Table (3) showed no statistically significant differences at the level of statistical significance $(\alpha=0.05)$ in the means of the study sample scoreson the total scale due to gender.

The results of the third question: Are there any significant differences $(a=0.05)$ in the role of sports activities in improving the level of self-esteem among physically disabled athletes in Jordan due to the variable of duration of injury ( $\leq 5$ years) and ( $>5$ years $)$ ? To answer this question,means, standard deviations, and ( $t$-test) calculated for the scores of the study sample on the total scale regarding the role of sports activities in improving the level of self-esteem of physically disabled athletes in Jordan, according to the duration of injury variable, as illustrated in table (4).

Table (4): means, standard deviations, and (t-test) to the scores of the study sample on the total scale of the role of sports activities in improving the level of self-esteem of physically disabled athletes in Jordan based on the duration of injury

\begin{tabular}{|l|l|l|l|l|l|l|l|}
\hline Scale & Duration of injury & No. & M. & St. D & T-value & Freedom degree & Sig. level \\
\hline $\begin{array}{l}\text { Total level of } \\
\text { self-esteem }\end{array}$ & ( $\leq 5$ years) & 35 & 3.32 & 0.37 & 1.080 & 62 & 0.288 \\
\cline { 2 - 5 } & (> 5 years) & 29 & 3.17 & 0.43 & & & \\
\hline
\end{tabular}

*Statistically significant at the significance level $(\square=0.05)$

Table (4) indicated that there were no statistically significant differences at the level of $(\alpha=0.05)$ in the means of the study sample on the total scaleof the role of sports activities in improving the level of self-esteem of physically disabled athletes in Jordan due to duration of injury.

\section{Discussion}

- Results showed that the mean of the participants' estimates of the role of sports activities in improving the level of self-esteem of physically disabled athletes in Jordan was (3.26) and with medium level of selfesteem. This is attributed to the role of sporting activities inimproving the self-accept and self-esteem of the physically disabled athletes and their social inclusion and sense of adaptation, they are respectful members of the community, and that the participation in these activities makes them able to overcome their problems and disability and sense of their social status. The medium level of self-esteem among the physically disabled athletes is due to the importance of sporting activities which earned the physically disabled individual positive experiences of success as a result of exercises, which in turn raise their self-confidence and self-esteem for themselves. The current results are consistent with the results of Cazenave, et al(2006), which showed that the level of self-esteemamong the physically disabled wasmedium.

- The results showed no statistically significant differences in the means ofscores of study sample on the total scale due to the variables of gender and duration of injury. This is attributed to the practice of sports activities among the physically disabled, whichcontributed to improving self-esteem they have based on different groups of gender and duration of injury, where field contributionincreased the practice of sports, as well as an increase in gettingrespected by others, empowered and sociallyaccepted and having highselfconfidence and self-esteem. They also felt the aspects of their positive abilities. The current results are consistent with the results of Cazenave, et al(2006), which showed no differences in the practice of sports 
activities to improve self-esteem among the physically disabled due to the variable of gender, and the results of Khoja (2011), which showed no differences in self-esteem among the physically disabled due to gender, but the results disagreedwith that of Cazenave, et al (2006), where it showed differences in the duration of injury in favor of the severe.

\section{Recommendation}

1. Conducting similar studies on the physically disabled athletes of various sports.

2. Taking into account the media respects for the physically disabled athletes to maintain their self-esteem and raise their self-confidence.

3. Conducting another similar study for comparison between the normal and the physically disabled.

\section{References}

[1]. Abdel-Hafeez and Bahi.(2001). Sports meeting. Cairo: book publishing center.

[2]. Abu Obeid, Faleh. (2004). Effectiveness of swimming educational program on the development of self-concept level and the skill level of individuals with mobility challenges. Unpublished MA Thesis, Faculty of Physical Education. Jordan, Yarmouk University.

[3]. Abu-Assad, Ahmed. (2009). Psychological and educational testing guide. Beirut: De Bono for printing, publishing and distribution.

[4]. Aldahri, Saleh. (2005). Psychology of caring for the Gifted and talented and those with special needs. Amman: Dar Wael.

[5]. Aldhidan, Hamidi. (2003). Self-esteem and its relationship to aggressive behavior among middle school students in Riyadh.Unpublished MA Thesis, the Naif Arab Academy for Security Sciences, Riyadh.

[6]. Alkakly, Badria. (2002). physically disabled perception for others and the formation of his self-concept.Unpublished MA Thesis, Fatih University, Faculty of Social Sciences, Social Care Department, Libya.

[7]. Alwan, Bashir. (2006). Life satisfaction and its relationship to self-esteem: comparative study between practitioners and nonpractitioners of sports activity for the physically disabled in Jordan. Unpublished doctoral dissertation, Faculty of Graduate Studies, University of Jordan, Jordan.

[8]. Bataineh, Osama and Muqableh, Nasr. (2004). Problems of mobility disabled individuals of Irbid, Jordan: An Analytical Study. Journal of Educational and Psychological Sciences, University of Bahrain, 6 (1): 67-100.

[9]. Behr.P \&Minotti.B. (2000). Les Effets de la Pratique du basket Fauteuil de hantNiveausurl'estimedesoi,congrés international dela SFPS-paris.

[10]. Cazenave, N. Peultier, A. S. and Lefort, G. (2008).L'activité physique et sportive et l'estime de soi chez les adolescents handicapés : le cas de la pathologie du pied bot Sport, physical activity and self-esteem in disabled adolescents: The case of clubfoot pathology. Annales Médico-psychologiques, revue psychiatrique. 166 (10): 789-793.

[11]. Farhat, Muhammad. (2004). Psychology of amputees: Amputation of body organ and its relationship to some personality traits. Cairo: Zahra Alsharq Bookstore.

[12]. Hassan, Iman. (2007). Motor disability: Psychodynamics study on amputees, the first scientific conference, special education between reality and expectations, Faculty of Education, Benha University, Egypt.

[13]. Ibrahim,Helmiand Farhat, Lily.(1998). Physical education and recreation for people with disabilities. Cairo: Dar AlfikrAlaraby.

[14]. James. O. Rust. (2000). Self- Esteem and Self -Efficacy of College Students with Disabilities.British Journal of Psychiatry. (15). $476-488$.

[15]. Kafafy, Ala. (1997). Mental Health. Vol. 4, Cairo: printing, publishing and distribution house.

[16]. Khoja, Adel. (2011). Effect of proposed sports program on improving the shape of the body and the concept of self-esteem among the physically disabled.Najah University Journal for Research (Humanities), 25 (5): 1284-1336.

[17]. Kholi, Ameen. (2001). Assets of physical education and sports: Introduction, history, philosophy. Vol. 3, Cairo: Dar Alfikralaraby.

[18]. Momni, Hana. (2006). Self-esteem and its relationship to educational level, age and way of movement to the visually impaired.Unpublished MA Thesis, Arab University, Amman, Jordan.

[19]. Oates, M. (2004). Does a Recreational Swimming Program Improve the Self-esteem of Children and Adolescents with Physical Disabilities: Possible Underlying Mechanisms. Masters thesis, Memorial University of New foundland. Teri. R. Blake.

[20]. Roussan, Farouk. (2007). The psychology of exceptional children. 7, Oman: Dar Alfikr.

[21]. Solomon, Abdul Rahman. (2001). Physical Disability: concept, classifications, and therapeutic methods. Cairo: Zahra AlsharqBookstore.

[22]. Wetterhahn K A, Hanson C, and Levy C E.(2002). Effect of Participation in Physical Activity on Body Image of Amputation.Journal of Physical Medicine of Rehabilitation,81(3):194-201. 